\title{
INCENTIVOS, ESTRUTURA BÁSICA E COMUNIDADE DE JUSTIFICAÇÃO: A CRÍTICA DE COHEN A RAWLS REVISITADA
}

[MOTIF, BASIC STRUCTURE AND COMMUNITY OF JUSTIFICATION: COHEN'S CRITIQUE TO RAWLS REVISITED]

\author{
Leandro Martins Zanitelli* \\ Universidade Federal de Mnas Gerais, Brasil
}

\begin{abstract}
Resumo: o artigo se ocupa de dois argumentos usados por Gerald Cohen em sua crítica à justiça dos incentivos que, segundo a j interpretação mais comum, são admitidos pela concepção de justiça de John Rawls - em particular, pelo princípio da diferença. Um desses argumentos é o que Cohen antecipa em resposta à objeção da estrutura básica, a objeção de acordo com a qual a crítica aos incentivos esbarra no limite que o próprio Rawls impõe à aplicabilidade dos princípios da justiça como equidade. $\mathrm{O}$ outro argumento apela para o ideal de uma comunidade de justificação a fim de defender uma interpretação do princípio da diferença incompativel (ao menos na maioria dos casos) com incentivos. A tese do artigo é a de que ambos os argumentos falham; o primeiro, porque não há incongruência em postular que uma concepção de justiça se aplique a estruturas ou regras sociais não coercivas, mas não aos comportamentos individuais que constituem essas estruturas; o segundo, porque pressupõe uma concepção de justiça formalmente diferente da de Rawls.
\end{abstract}

Palavras-Chave: Rawls; Cohen; incentivos; princípio da diferença; estrutura básica; comunidade de justificação
ABSTRACT: the article deals with two arguments used by Gerald Cohen in his critique of the justice of incentives that, according to the most common interpretation, are admitted by John Rawls's conception of justice - in particular, by difference principle. One such argument is what Cohen anticipates in response to the basic structure objection, the objection according to which the criticism of incentives runs up against the limit that Rawls himself imposes on the applicability of the principles of justice as fairness. The other argument calls for the ideal of a community of justification in order to defend an interpretation of difference principle incompatible (at least in most cases) with incentives. The article's thesis is that both arguments fail; the first, because there is no incongruity in postulating that a conception of justice applies to non-coercive social structures or rules, but not to the individual behaviors that constitute these structures; the second, because it presupposes a conception of justice formally different from that of Rawls.

KeYwORDS: Rawls; Cohen; incentives; difference principle; basic structure; community of justification

\section{INTRODUÇÃO}

presente artigo revisita a crítica de Gerald Cohen à justiça dos incentivos isto é, às vantagens demandadas por certos cidadãos como condição para que façam uso de seus talentos de maneira socialmente desejável. A crítica de Cohen aos incentivos é endereçada a John Rawls, cuja concepção de justiça, a justiça como

* Doutor em Direito pela Universidade Federal do Rio Grande do Sul, UFRGS. Professor Adjunto na Faculdade de Direito da Universidade Federal de Mnas Gerais, UFMG. E-mail: leandrozanitelli@gmail.com 
equidade, ${ }^{1}$ costuma ser tido como condizente com incentivos.

Dois argumentos de Cohen são considerados a seguir. O primeiro deles é um argumento que Cohen apresenta como resposta à objeção da estrutura básica - à objeção, isto é, de que a justiça, tal como Rawls a concebe, é compativel com incentivos porque o objeto primário da justiça é a estrutura básica da sociedade, e não as ações individuais praticadas no interior dessa estrutura. De acordo com esse argumento, a justiça como equidade seria uma concepção de justiça arbitrária caso se ocupasse apenas da estrutura formal - isto é, de instituições juridicas -, e não pode se estender a instituições não jurídicas ou informais sem se aplicar também às ações individuais graças às quais essas últimas instituições subsistem.

O segundo argumento - designado abaixo como argumento da comunidade de justificação - apela para uma característica valiosa de politicas públicas, a saber, a de que essas políticas não apenas se justifiquem em si mesmas, mas que tenham em vista comportamentos que sejam também eles justificados. Como, para Cohen, políticas de incentivo não atendem a esse último requisito, uma sociedade na qual essas políticas de incentivo são praticadas não é uma comunidade de justificação.

Contra Cohen, afirmo a seguir que o argumento em resposta à objeção da estrutura básica falha, enquanto o argumento da comunidade de justificação não é defensável como crítica interna a Rawls, porque depende de uma concepção de justiça estruturalmente diversa da concepção de justiça procedimental pura que Rawls tem em vista.

O artigo é organizado da seguinte maneira. Na seção 1 , em preparação à análise do argumento sobre a objeção da estrutura básica, defendo a tese de que, se o objeto da justiça tiver de se limitar a certas instituições, essas instituições devem ser definidas segundo o critério de impacto, e não o critério da coerção (estatal). A seção 2 responde ao argumento de Cohen sobre a objeção da estrutura básica. Minha tese nessa seção é, em suma, a de que não há incongruência em submeter estruturas sociais informais a certos parâmetros de justiça sem, ao mesmo tempo, aplicar tais parâmetros às ações individuais que constituem essas estruturas. As seções restantes do artigo se voltam ao argumento da comunidade de justificação. Enquanto a seção 3 reproduz esse argumento, nas duas seções seguintes, 4 e 5, uma premissa crucial do argumento, a premissa segundo a qual "a recusa por parte de cidadãos talentosos a realizar independentemente de incentivos (incentivos que os põem em vantagem sobre os demais) um trabalho que poderiam realizar mesmo à falta desses incentivos é injustificável", é posta em xeque. A seção 4 se ocupa com dois argumentos, ao meu ver não definitivos, contra a injustificabilidade da recusa por parte de cidadãos talentosos a trabalhar independentemente de incentivo, os argumentos da liberdade de ocupação e das obrigações especiais. A seção 5 trata, finalmente, da diferença estrutural entre a concepção de justiça para a qual o argumento da comunidade de justificação apela e o caráter procedimental puro da concepção de justiça de Rawls.

\section{O CRITÉRIO DO IMPACTO}

Esta seção defende pro tanto o critério do impacto para delimitar o objeto da justiça. Trata-se de uma defesa pro tanto, porque nenhum argumento é aduzido em favor da conclusão de que o objeto da justiça seja circunscrito, isto é, de que, de tudo o que se poderia, em tese, designar como justo ou injusto, nossas considerações se restrinjam a uma parte - por exemplo, a parte das instituições sociais ou parte dos comportamentos que ocorrem sob elas. Meu argumento será o de que, se tivermos que limitar nosso objeto de análise quanto a questões de justiça, o critério do impacto é um critério plausivel.

Segundo o critério do impacto, são objeto da justiça as instituições e 
comportamentos cujo impacto sobre as expectativas dos cidadãos sejam mais consideráveis. Essas instituições, ou regras sociais, podem ser formais ou informais, isto é, podem ser jurídicas (instituições formais) ou consistir simplesmente em padrões comportamentais sancionados socialmente (instituições informais). Ainda de acordo com o critério do impacto, comportamentos individuais também podem ser objeto da justiça, mas apenas na hipótese (excepcional) em que esses comportamentos surtam um efeito comparável ao das principais instituições sociais.

Não é preciso aqui tratar em detalhe das expectativas dos cidadãos a que o critério do impacto se refere, o que nos defrontaria com o bem conhecido problema da métrica da justiça. Trata-se de expectativas quanto à utilidade, bens primários ou capabilidades? Essa questão pode ser aqui posta de lado, de maneira que podemos tratar o critério do impacto como critério que limita a investigação sobre a justiça às instituições que influenciam decisivamente as expectativas dos cidadãos que sejam relevantes para a justiça, como quer que essas expectativas se definam, isto é, como expectativas quanto à utilidade, bens primários, capabilidades ou qualquer outra métrica.

À primeira vista, e nos termos em que a questão foi posta acima, o critério do impacto soa plausível - óbvio, até. Afinal, se tivermos que restringir nosso objeto de análise no que se refere à justiça, decerto que parece melhor dirigir nossa atenção às instituições (e, eventualmente, comportamentos) com maior impacto sobre as expectativas dos cidadãos - ao invés de àquelas cuja influência sobre essas expectativas seja negligenciável. Gostaria, não obstante, de defender o critério do impacto contra um critério alternativo, o critério da coerção (estatal). Segundo esse outro critério, as instituições a se submeterem ao crivo da justiça são instituições coercivas - isto é, regras cuja observância é amparada pela ameaça de uso da força estatal.

A fim de comparar os méritos dos dois critérios, partirei da diferença quanto às suas implicações para as instituições informais, isto é, padrões de comportamento sancionados socialmente, mas não juridicamente - tal como é frequentemente o caso, por exemplo, da divisão sexual do trabalho doméstico. De acordo com o critério do impacto, algumas dessas instituições informais, a depender do seu impacto, sujeitam-se aos preceitos da justiça. $\mathrm{O}$ critério da coerção, de outra parte, limita nossa investigação acerca da justiça às instituições formais, isto é, às regras cuja obediência é coercitivamente imposta pelo estado.

O problema com o critério da coerção não é tanto a importância que atribui à coerção. Afinal, à pergunta “o que a coerção tem de tão especial?" se poderia responder com uma alusão ao monopólio da violência pelo estado - embora ainda seja de indagar se a peculiaridade da coerção estatal justifica tratá-la como objeto exclusivo da justiça, em detrimento da coerção difusa que decorre de práticas e estruturas sociais. O principal problema com o critério da coerção, contudo, é que ele depende de uma concepção implausível dos direitos que cidadãos livres e iguais devem reconhecer uns aos outros. $\mathrm{O}$ critério da coerção só se sustenta se esses direitos forem concebidos unicamente como direitos de cada um contra o estado. Tal concepção restritiva dos direitos implica que somente a atuação estatal é capaz de violar direitos, mostrando-se, como tal, compativel com uma restrição análoga do objeto da justiça. Uma vez, no entanto, que os direitos em questão se entendam como direitos que os cidadãos se concedem reciprocamente uns contra os outros (muito embora se trate de direitos cuja concretização dependa de uma regulação jurídica e, em consequência, de atos de autoridade), a razão para que a justiça não se ocupe também, e até primariamente, de práticas sociais - dentre elas, as que dão lugar a ou reforçam instituições informais - desaparece.

Voltando ao exemplo da divisão sexual do trabalho doméstico, o que designei acima como concepção restritiva de direitos implicaria afirmar que, se há alguma violação de direito envolvida no fato de a mulher se ocupar desproporcionalmente com o cuidado da casa e dos filhos, essa violação residiria tão-somente em alguma ação 
estatal (ou, mais provavelmente, uma omissão). Essa concepção é, contudo, implausível. Se há algo verdadeiramente errado no fato de o trabalho doméstico recair desproporcionalmente sobre as mulheres, o erro reside antes de tudo nesse fato em si, e apenas secundariamente na falta de medidas jurídicas que se contraponham a essa prática. Em outras palavras, são antes de mais nada as práticas atuais de divisão do trabalho doméstico que sonegam às mulheres um direito que, como cidadãs livres e iguais, lhes assiste.

O argumento recém exposto se sujeita a duas objeções. A primeira é a de que os direitos são parasitários da justiça: para determinar os direitos que cabem aos participantes de uma associação politica, é preciso inquirir, antes, o que a justiça requer no âmbito de uma associação assim. A segunda objeção é a de que falar sobre direitos equivale a falar sobre justiça, de maneira que afirmar, por exemplo, que as práticas informais de divisão do trabalho doméstico atentam contra um direito das mulheres equivale a afirmar que essas práticas são injustas. No primeiro caso, o argumento se equivoca quanto à ordem lógica entre direitos e justiça, enquanto que, no segundo, tratase de um argumento circular.

Em resposta às duas objeções, há uma razão para que uma certa concepção sobre os direitos, ainda que um tanto abstratos, dos cidadãos se repute anterior à justiça, bem como, em consequência, para negar que discursos sobre direitos e sobre justiça sejam equivalentes. É que, ao afirmar que uma associação política é baseada em direitos que os cidadãos reconhecem uns aos outros, expressamos a natureza dessa associação de um modo como concepções de justiça, ou mesmo um conceito abstrato de justiça como não arbitrariedade ( $T J$, p. 5), não são capazes de fazer ou fazem apenas implicitamente. Tendo em vista a importância de que se reveste uma definição sobre o caráter das relações sociais, faz sentido, portanto, que comecemos com os direitos - ou com a ideia geral de sociedade como associação baseada no reconhecimento de direitos mútuos - e que entendamos diferentes concepções de justiça social ou política como realizações ou "especificações" dessa ideia fundamental. ${ }^{2}$

\section{INCENTIVOS E A OBJEÇÃo DA ESTRUTURA BÁSICA}

Em "Rescuing Justice and Equality", Gerald Cohen (COHEN, 2008; doravante, $R J E$ ) critica a interpretação segundo a qual o princípio da diferença de Rawls respalda o comportamento de cidadãos que condicionam o uso produtivo das suas capacidades a incentivos que, uma vez concedidos, premiam desigualmente os cidadãos em questão. Cohen acusa essa interpretação do princípio da diferença, que ele designa como frouxa (lax), de ser incompativel com a concepção de justiça de Rawls, a justiça como equidade.

Um dos alvos de Cohen é o fato de a interpretação frouxa levar à conclusão de que cidadãos talentosos (o modo como ele se refere aos cidadãos cuja capacidade produtiva é altamente demandada) que condicionam o uso de seus talentos a incentivos desiguais (isto é, causadores de desigualdade ${ }^{3}$ ) não cometem uma injustiça. Cohen antecipa, no entanto, um argumento em defesa dessa conclusão, o que ele designa como objeção da estrutura básica. De acordo com essa objeção, não há incongruência em afirmar que, do ponto de vista da concepção de justiça de Rawls, cidadãos talentosos não ajam injustamente ao reclamar por incentivos desiguais, uma vez que a concepção em questão é uma concepção de justiça para a estrutura básica da sociedade (isto é, para as instituições sob as quais a cooperação social tem lugar), e não para as ações individuais praticadas nos limites dessa estrutura. ${ }^{4}$

Para responder à objeção da estrutura básica, Cohen presume que o critério à base do qual a teoria da justiça de Rawls circunscreve o objeto da justiça seja o do 
impacto (RJE, p. 136). Ele faz, então, duas afirmações, uma das quais é trivial: a razão para que a conduta dos cidadãos talentosos não se sujeite ao crivo da justiça não pode ser a de que a estrutura básica da sociedade se compõe tão-somente de medidas coercivas, porque essa concepção de estrutura básica é incompativel com o critério do impacto (RJE, p. 137).

A segunda afirmação, mais intrincada, é a seguinte. Uma vez que o critério do impacto leva a tratar como objeto da justiça tanto as instituições formais, ou coercivas, quanto as informais (contanto que seu impacto sobre as perspectivas dos cidadãos seja considerável), então não há como condutas individuais, como as de cidadãos talentosos que demandam incentivos, ficarem à margem da justiça, já que instituições informais "are bound up with the choices that people customarily make." (RJE, p. 134).

Valendo-se do exemplo da família, ele esclarece:

\begin{abstract}
"Bound up with" is vague, so let me explain how I mean it here. One can certainly speak of the structure of the family, and it is not identical with the choices that people customarily make within it; but it is nevertheless impossible to claim that the principles of justice that apply to family structure do not apply to day-to-day choices within it. For consider the following contrast. The coercive structure, let us provisionally accept, arises independently of people's quotidian choices: it is formed by those specialized choices that legislate the law of the land. But the noncoercive structure of the family has the character it does only because of the choices that its members routinely make. The constraints and pressures that sustain the noncoercive structure reside in the dispositions of agents that are actualized as and when those agents choose to act in a constraining or pressuring way. With respect to coercive structure, one may perhaps fairly readily distinguish the choices that institute and sustain a structure from the choices that occur within it. But with respect to informal structure, that distinction, though conceptually intelligible, is compromised extensionally: when A chooses to conform to the prevailing usages, the pressure on B to do so is reinforced, and no such pressure exists, the very usages themselves do not exist, in the absence of conformity to them. Structure and choice remain distinguishable, but not from the point of view of the applicability to them of principles of justice (at any rate when, as is ex hypothesi the case here, they are thought to apply because of the fateful consequences of that to which they apply: you cannot bring the informal norm within the compass of justice for that reason without also bringing within its compass the actions that give the norm substance and that account for much, if not most, of its effect). (RJE, pp. 134-135 - notas de rodapé omitidas).
\end{abstract}

Nessa passagem, Cohen diferencia estruturas informais (ou não coercivas) e ações individuais. Embora distinguíveis, estruturas e ações individuais estão amarradas (bound up) no sentido de que as primeiras são constituídas pelas segundas. Instituições informais como a divisão sexual do trabalho doméstico envolvem não apenas um comportamento regular como também um certo ponto de vista interno - o que Herbert Hart (HART, 1994, cap. V) chama de aceitação de uma regra - o qual se manifesta, por exemplo, na crítica a condutas desviantes. Aqui podemos pôr de lado a diversidade de condutas e atitudes (incluindo o comportamento repetido e as críticas aos desvios) que constituem uma estrutura informal para falar, simplesmente, em ações individuais e estruturas. A tese de Cohen na passagem acima é uma tese sobre o status frente à justiça de uma estrutura $X$ que subsiste graças (em parte) a uma certa conduta individual $Y$. Sobre o conteúdo da tese, no entanto, há ao menos duas interpretações:

(t1) Se uma estrutura $X$ é injusta, então toda conduta individual, como $Y$, que constitui essa estrutura também é, necessariamente, injusta.

t1 é implausível. Podemos, sem dúvida, afirmar que a divisão sexual do trabalho doméstico, como estrutura social, é injusta, porque limita as oportunidades das 
mulheres, mas, ao mesmo tempo, admitir que, em certos casos, ao menos, uma conduta individual que sustenta essa estrutura não é injusta. Certos casais podem ter boas razões para dividir o trabalho doméstico de tal maneira a que a mulher fique encarregada de toda ou boa parte desse trabalho - por exemplo, tendo em vista o interesse em não delegar a terceiros o cuidado com os filhos e a maior capacidade do homem para auferir renda. Parece perfeitamente coerente afirmar que não há nada de injusto no comportamento desses casais e insistir que, não obstante, como regra social, a divisão sexual do trabalho doméstico é injusta. ${ }^{5}$

Outro ponto aqui é que as razões que justificam um comportamento individual podem ter raizes na prática injusta (prática essa que o comportamento em questão reforça). $\mathrm{O}$ fato de a capacidade superior do homem para auferir renda poder ser atribuido a estruturas sociais injustas (por exemplo, a estereótipos que inibam a mulher a investir em uma carreira ou à discriminação no trabalho) não impede que, devido às circunstâncias, a decisão de um casal de entregar à mulher o cuidado com os filhos se justifique. O próprio fato de escolhas individuais se realizarem no interior de estruturas é também uma razão, portanto, para que a injustiça de uma estrutura $X$ não implique a injustiça de um comportamento individual $Y$ que constitui $X{ }^{6}$

Ao invés de $t 1$, o que Cohen pode ter em mente então é:

(t2) Se uma estrutura $X$ é objeto da justiça, então toda conduta individual, como $Y$, que constitui essa estrutura também é, necessariamente, objeto da justiça.

$t 2$ se diferencia de $t 1$ porque não diz que qualquer juizo que valha para $X$ necessariamente valerá também para $Y$. $t 2$ é compativel, por exemplo, com que consideremos $X$ injusta sem afirmar o mesmo de $Y$.

A conclusão de $t 2$, no meu modo de ver, é correta, embora tenha dúvida de que essa conclusão seja implicada pela premissa. Em todo o caso, não importa, porque, ao substituir $t 1$ por $t 2$, a resposta de Cohen à objeção da estrutura básica perde força. Se, como $t 2$ admite, os princípios a que $X$ se subordina não forem os mesmos de $Y$, então não é arbitrário que uma certa concepção de justiça se aplique a $X$ e não a $Y$. Esse poderia ser o caso da concepção de justiça de Rawls, se os princípios dessa concepção forem princípios válidos apenas para a estrutura básica da sociedade, entendendo-se como parte dessa estrutura as instituições, formais e informais, cujo impacto sobre as expectativas dos cidadãos seja considerável.

Diferentemente do que Cohen dá a entender, portanto, Rawls pode afirmar que o princípio da diferença se aplica a estruturas sociais, mas não as ações individuais verificadas no interior dessas estruturas, sem ter que, ao mesmo tempo, renunciar ao critério do impacto e limitar as estruturas em questão às estruturas coercivas. $\mathrm{O}$ fato de $\mathrm{o}$ princípio da diferença não se aplicar a ações individuais - em particular, às escolhas dos agentes no mercado - não implica que esse princípio corrobore uma estrutura básica que inclua incentivos (desiguais) aos cidadãos talentosos para que empreguem sua força produtiva de modo socialmente desejável. Contra a conclusão de que o princípio da diferença é compatível com uma estrutura de incentivos, porém, Cohen levanta uma outra objeção, à qual passarei na seção seguinte.

\section{INCENTIVOS E COMUNIDADE}

Esta seção apresenta outra das críticas de Cohen aos incentivos desiguais (isto é, causadores de desigualdade ${ }^{7}$ ) que, segundo certa interpretação, são ao menos permitidos (quando não tidos como obrigatórios ${ }^{8}$ ) pelo princípio da diferença. Cohen distingue duas interpretações desse princípio (RJE, pp. 68-69). Em ambas, o princípio da diferença permite desigualdades que sejam necessárias a melhorar a situação dos cidadãos em desvantagem; o que diferencia as duas interpretações é o que se entende como desigualdade necessária. No caso da interpretação frouxa (lax), uma desigualdade é 
necessária também se, à falta dela, alguns cidadãos (os cidadãos que Cohen tem em vista aqui são, como dito, aqueles cujo trabalho é altamente demandado) não farão algo que lhes é possível fazer e que, caso feito, beneficiaria os cidadãos em pior situação. Em contrapartida, de acordo com a interpretação estrita, desigualdades não são necessárias se elas constituem uma condição voluntariamente imposta por alguns cidadãos, isto é, se forem uma condição para que esses cidadãos façam algo que seriam capazes de fazer (embora o recusem) mesmo à falta de incentivo.

O problema de Cohen é com os incentivos que estão em desconformidade com a interpretação estrita mas são admitidos pela interpretação frouxa do princípio da diferença. É um problema, em outras palavras, com incentivos para que certos cidadãos contribuam para a boa sorte dos demais - por exemplo, trabalhando mais duro ou em atividades nas quais seus talentos sejam mais úteis - em casos nos quais o mesmo trabalho poderia ser (mas não seria $^{9}$ ) prestado pelos cidadãos em questão independentemente de incentivo.

Antes de passar ao argumento, há dois pontos que gostaria de salientar. O primeiro é que o embate entre as interpretações estrita e frouxa do princípio da diferença é independente da questão de saber se esse princípio se aplica apenas à estrutura básica da sociedade (e se essa estrutura se limita a instituições coercivas ou também inclui as não coercivas) ou também às ações individuais. Mesmo que restringíssemos a aplicação do princípio da diferença à estrutura básica (ou apenas às instituições coercivas), ainda assim teriamos que decidir entre as duas interpretações para saber se instituições que conferem incentivos a cidadãos que poderiam trabalhar independentemente desses incentivos (mas não estão dispostos a fazê-lo) conformam-se ou não ao princípio em questão.

Outro ponto é que a escolha entre as interpretações estrita e frouxa tanto pode ser cogitada como escolha das partes na posição original de Rawls quanto como escolha dos cidadãos de uma comunidade política que deseje adequar suas instituições ao princípio da diferença. Não está claro a qual dessas escolhas Cohen se refere em sua crítica, mas como o princípio da diferença é, juntamente com os demais princípios da justiça como equidade, um princípio escolhido na posição original, e como a diferença entre as duas interpretações é uma diferença substancial, poder-se-ia concluir que a decisão das partes na posição original já deveria incluir uma decisão em favor de uma das duas interpretações do principio. ${ }^{10} \mathrm{Nada}$ impede, contudo, que se pense na escolha entre as duas interpretações como uma escolha a ser feita por cidadãos - por cidadãos, isto é, que aceitam uma versão abstrata do princípio da diferença e que, para aplicá-la às suas instituições, terão de se decidir por uma das duas interpretações.

Passemos ao argumento. Para apresentá-lo, Cohen se vale do conceito de justificação abrangente de uma lei. Para que uma lei seja justificada abrangentemente, duas condições devem ser satisfeitas. Primeiro, se afirmamos que uma lei deve ser aprovada porque prevenirá certo comportamento, então uma condição de justificação é que essa expectativa seja uma razão para aprovar a lei. ${ }^{11}$ Em outras palavras: se defendemos uma lei $a$ sob a alegação de que essa lei evitará que alguns cidadãos façam $b$, é uma condição de justificação a de que essa expectativa - de que os cidadãos façam $b$ - seja uma razão para aprovar $a$ (por exemplo, porque $b$ é um comportamento indesejável ou infringe alguma prescrição moral). Para uma justificação abrangente, no entanto, é também preciso, em segundo lugar, que a conduta que a lei previne seja uma conduta justificada. Não basta, pois, para a justificação abrangente, que $a$ seja de molde a evitar $b$ (e que esse fato seja uma razão para promulgar $a$ ); é também preciso que aqueles que realizariam $b$ estivessem justificados ao fazê-lo.

O caso de justificação abrangente que Cohen tem em vista é, naturalmente, o de uma lei que confira incentivos a fim de que os cidadãos talentosos não soneguem sua força de trabalho, trabalhando menos ou em atividades menos úteis. ${ }^{12} \mathrm{Na}$ hipótese em 
que esses cidadãos poderiam realizar o trabalho em questão independentemente de incentivos, ${ }^{13}$ a recusa em trabalhar ${ }^{14}$ (conduta $b$ ) é, segundo Cohen, injustificável. Logo, verificada essa hipótese, uma lei de incentivo não estará abrangentemente justificada.

Mas por que a justificação abrangente é importante? Por que não é o bastante que uma lei se justifique pelo seu impacto comportamental, mas também que o comportamento que a lei incentiva a não ter seja um comportamento justificado? Para responder, Cohen invoca o ideal de uma comunidade de justificação (RJE, pp. 43-44). Esse ideal fica aquém de ser totalmente realizado em uma comunidade politica se certas decisões são alcançadas tendo em vista comportamentos de alguns dos participantes dessa comunidade que não é possível justificar. Uma lei que se valha de sanções (ou prêmios) para prevenir esses comportamentos aliena os cidadãos em questão, tratandoos como incapazes de responder a razões. ${ }^{15}$

$\mathrm{O}$ argumento pode então ser desdobrado da seguinte maneira:

(1) O ideal de uma comunidade de justificação é um ideal a ser perseguido pelos participantes de uma comunidade política.

(2) O ideal de uma comunidade de justificação somente é completamente realizado se as decisões de uma comunidade politica são abrangentemente justificadas.

(3) A recusa por parte de cidadãos talentosos a realizar independentemente de incentivos (incentivos que os põem em vantagem sobre os demais) um trabalho que poderiam realizar mesmo à falta desses incentivos é injustificável.

(4) Leis que conferem incentivos na hipótese a que se refere a premissa 3 não são suscetiveis de justificação abrangente.

(5) Leis que conferem incentivos na hipótese a que se refere a premissa 3 impedem que uma comunidade política realize o ideal de uma comunidade de justificação.

(6) Dentre diversas interpretações do princípio da diferença, é de se preferir, ceteris paribus, uma que não seja incompativel com a realização do ideal de uma comunidade de justificação.

(7) Diferentemente da interpretação estrita, a interpretação frouxa do princípio da diferença permite leis que conferem incentivos na hipótese a que se refere a premissa 3.

(8) Por não ser incompatível com a realização do ideal de uma comunidade de justificação, a interpretação estrita do princípio da diferença é preferível, ceteris paribus, à interpretação frouxa.

Embora as primeiras duas premissas sejam importantes, não pretendo me ocupar com elas. ${ }^{16} \mathrm{O}$ argumento falha, ao meu ver, porque a terceira premissa pressupõe uma concepção de justiça com a qual Rawls e seus seguidores não precisam estar de acordo, o que determina o insucesso da crítica aos incentivos como crítica interna a Rawls.

\section{RECUSA AO TRABALHO E JUSTIFICAÇÃO: DOIS ARGUMENTOS PRELIMINARES}

Segundo a terceira premissa do argumento reproduzido acima,

(3) A recusa por parte de cidadãos talentosos a realizar independentemente de incentivos (incentivos que os põem em vantagem sobre os demais) um trabalho que poderiam realizar mesmo à falta desses incentivos é injustificável.

Trata-se de é uma premissa crucial do argumento, já que é uma condição para afirmar 4, 5 e 8. Doravante, ela será designada como premissa-chave, PC

Antes de pôr PC à prova, é importante esclarecer o que se entende como recusa (ou, em geral, conduta) justificável. Embora Cohen não seja explícito a respeito, parece correto interpretá-lo no sentido de que uma certa conduta é justificável se não há uma ou mais razões morais suficientes para que essa conduta seja evitada. Não necessariamente, portanto, uma conduta justificável é uma conduta para a realização da qual há suficiente razão (moral): pode não haver nenhuma boa razão para que eu cantarole o hino 
brasileiro enquanto escrevo esta frase, mas se tampouco houver uma boa razão contrária a que eu faça isso (estou escrevendo na minha casa, sozinho, e não incomodarei a ninguém se começar a cantarolar o hino agora, etc.), minha conduta ao cantarolar o hino seria, no sentido que aqui se tem em vista, justificável. ${ }^{17}$

A questão que se põe, então, é a de saber se o argumento está correto ao reputar como injustificável a recusa dos cidadãos talentosos a realizar, independentemente de incentivo, um trabalho que lhes é possível fazer. Consideremos, para começar, dois argumentos - ao meu ver, não decisivos - no sentido de que há uma razão suficiente para o comportamento dos cidadãos talentosos.

Um desses argumentos, com o qual Cohen se ocupa no capítulo 5 de $R J E$, invoca o direito à liberdade - mais precisamente, à liberdade de ocupação. De acordo com esse argumento, a razão suficiente para que um cidadão capaz de trabalhar como médico, por exemplo, se recuse a realizar esse trabalho (para se dedicar, ao invés, à jardinagem) está em que essa recusa constitui o exercício de um direito - o direito à liberdade de ocupação - que não pode ser legitimamente sonegado a nenhum cidadão.

A resposta de Cohen a esse argumento é, em suma, a de que o direito à liberdade de ocupação não é negado a cidadãos que, a despeito de considerarem outras atividades mais valiosas, decidam-se espontaneamente (isto é, sem serem coagidos a tanto pelo estado) a realizar um trabalho socialmente mais útil. ${ }^{18}$ Tendo em vista, ademais, que o direito à livre ocupação pode ser exercido de mais de uma maneira, faz sentido, segundo Cohen, perguntar pelas razões para exercê-lo de uma maneira e não de outra. Em outras palavras: o direito à liberdade de ocupação não implica que não haja boas razões - e até razões suficientes - contra um particular modo de exercício desse direito. ${ }^{19}$

Outro argumento é o de que a recusa a realizar certo trabalho à falta de incentivo pode se justificar por certas obrigações especiais, como obrigações familiares ou o de reparar um dano causado a outrem. O cenário que se tem em vista aqui é um no qual certo trabalho, caso realizado, fará com que o agente necessite de recursos adicionais a fim de cumprir alguma obrigação especial. A recusa a trabalhar sem incentivo estaria justificada, em tal caso, por um principio segundo o qual é lícito a um agente recusar-se a fazer algo para não cair em uma situação na qual se veja forçado a descumprir uma obrigação. Esse princípio se sujeita, é claro, a limites - nem todos os meios são admissiveis - mas seria capaz de justificar, em alguns casos, ao menos, o comportamento dos cidadãos talentosos. Considere os exemplos a seguir: ${ }^{20}$

(Exemplo 1) João estudou direito e é professor universitário. Ele também poderia trabalhar como advogado (atividade na qual seus talentos seriam mais utilmente empregados). Como advogado, no entanto, João não conseguiria (não, ao menos, na medida que hoje o faz) repartir com sua companheira os cuidados com seu filho pequeno. Para abandonar as aulas pela advocacia sem sacrificar sua companheira, João teria, pois, de arcar com os custos de uma creche ou babá.

(Exemplo 2) Igual ao anterior, salvo que, desta vez, João cuida do filho de outra pessoa, uma mulher incapacitada por um acidente de trânsito causado por ele há algum tempo atrás. Caso decida se dedicar à advocacia, João pode entregar os cuidados da criança a uma creche ou babá, mas, para não descumprir seu dever indenizatório, teria de arcar com os respectivos custos. ${ }^{21}$

Ao menos em alguns cenários como esses - naqueles em que a obrigação que o cidadão talentoso seria forçado a descumprir caso trabalhasse mesmo à falta de incentivo tenha mais peso do que as considerações em favor de que esse trabalho se realize -, PC é falsa.

O problema com o argumento das obrigações especiais, no entanto, é que ele oferece uma base muito tênue para que uma lei de incentivos seja justificada abrangentemente. Para que uma lei de incentivos se justifique abrangentemente, lembrese, é necessário que essa lei previna um certo comportamento (no caso, a recusa ao 
trabalho) e que esse comportamento seja, em si mesmo, justificado. Aceitas essas premissas, a conclusão que o argumento das obrigações especiais permite tirar é que uma lei que confira incentivos a cidadãos talentosos que se veriam forçados a descumprir alguma obrigação especial (obrigação essa cujo peso seja suficiente para se sobrepor a considerações contrárias) caso trabalhassem sem incentivo está

54 abrangentemente justificada. Geralmente, no entanto, incentivos legais são dados indiscriminadamente, isto é, não apenas para cidadãos que se encontram nas peculiares circunstâncias que o argumento das obrigações especiais tem em vista. À falta de uma razão para que os incentivos sejam indiscriminados, é preciso reconhecer que leis de incentivos são promulgadas a fim de induzir ao trabalho cidadãos talentosos em geral, e não apenas aqueles que, devido a alguma obrigação especial, estariam justificados em se recusar ao trabalho.

É plausível que um caso especial de justificação abrangente seja o seguinte: "a lei $a$ se justifica porque prevenirá que alguns cidadãos façam $b$. Dentre os cidadãos que farão $b$ caso $a$ não seja promulgada, alguns estariam justificados em agir assim, mas outros não. Há, no entanto, razão suficiente para que sequer tentemos reduzir a aplicabilidade de $a$ aos cidadãos que estariam justificados em fazer $b$." É difícil, porém, imaginar que razão seria essa no caso de uma lei de incentivos - ou de qualquer outra. Nos casos em que o status de $b$ varia - isto é, em que $b$ por vezes se justifica, por vezes não -, pode ser difícil, senão impossível, calibrar a lei de maneira a que ela só se aplique na primeira hipótese. Por si só, contudo, essa dificuldade não é razão - se estivermos de fato comprometidos com o ideal de uma comunidade de justificação - para que não tentemos limitar o âmbito da lei, tanto quanto possível, aos casos em que $b$ é justificada.

\section{RECUSA AO TRABALHO E JUSTIFICAÇÃO: DE VOLTA À OBJEÇÃO DA ESTRUTURA BÁSICA}

O problema central com PC é que ela recorre a uma concepção de justiça diferente da de Rawls, o que faz com que o argumento da comunidade de justificação, como crítica interna a Rawls, fracasse. Voltemos, uma vez mais, a essa premissa. Segundo ela:

(PC) A recusa por parte de cidadãos talentosos a realizar independentemente de incentivos (incentivos que os põem em vantagem sobre os demais) um trabalho que poderiam realizar mesmo à falta desses incentivos é injustificável.

$\mathrm{O}$ argumento de Cohen para afirmar que a recusa ao trabalho pelos cidadãos talentosos é injustificável é um argumento de justiça. Qual é esse argumento? À primeira vista, poderíamos afirmar que o princípio de justiça infringido pelos cidadãos talentosos é o princípio da diferença. Afinal, esse princípio somente permite desigualdades que sejam necessárias a melhorar a situação dos cidadãos em desvantagem, e os cidadãos talentosos, ao se recusarem a trabalhar à falta de incentivos, reclamam para si um benefício que não é necessário a que os interesses dos demais cidadãos sejam atendidos. Mesmo que, em si mesma, a recusa ao trabalho não cause a desigualdade - a causa da desigualdade são os incentivos, e não a recusa ao trabalho -, essa desigualdade é imputável aos cidadãos talentosos, que impõem à comunidade a difícil escolha entre dar incentivos e a pobreza.

Um problema com essa resposta é que, como é perceptível, ela se baseia não apenas no princípio da diferença, mas em uma particular interpretação desse princípio, a interpretação estrita, porque é essa interpretação (ao contrário da interpretação frouxa) que trata a desigualdade decorrente de um comportamento voluntário de alguns cidadãos como desigualdade injustificada. Isso é um problema porque PC é uma premissa de um argumento, o argumento da comunidade de justificação, cujo propósito não é outro 
senão ajuizar entre as duas interpretações, estrita e frouxa, do princípio da diferença. Assim, ao tratar PC como premissa segundo a qual a recusa ao trabalho pelos cidadãos talentosos é injustificável porque afronta o princípio da diferença, estaríamos pressupondo não apenas esse princípio como princípio de justiça, mas uma particular interpretação dele - justamente a interpretação que o argumento se propõe a corroborar.

Cohen poderia se furtar a esse problema se o princípio de justiça à base de PC fosse outro que não o princípio da diferença na sua interpretação estrita. Qualquer que fosse, no entanto, esse outro princípio teria de se revestir de certas caracteristicas sem as quais não poderia ser o princípio à base do qual se afirma que a recusa dos cidadãos talentosos ao trabalho é injustificável. Para ter essa implicação, o princípio em questão teria de ser um princípio aplicável a ações individuais e capaz de julgar como justas ou injustas essas ações segundo suas consequências - mais precisamente, segundo suas consequências quanto à distribuição de certos bens. Só assim esse princípio poderia reputar como injustificável a recusa ao trabalho porque atenta contra os interesses dos cidadãos em pior situação e força uma distribuição - a distribuição decorrente de incentivos - em que os cidadãos talentosos se encontram em situação melhor do que aquela em que necessitariam estar a fim de melhorar a sorte dos demais cidadãos.

Nenhuma dessas características é uma característica dos princípios da concepção de justiça de Rawls, e essa é a razão fundamental para que PC e, com ela, o argumento da comunidade de justificação fracassem como crítica interna a Rawls. Quanto à primeira característica, os princípios da justiça como equidade são, como dito, princípios aplicáveis à estrutura básica da sociedade, e não às ações individuais que se praticam no interior dessa estrutura. Acima, na seção 2, vimos que não há incongruência em definir a estrutura básica - e, portanto, o objeto dos princípios da justiça, para Rawls - de maneira a incluir nessa estrutura instituições informais e, ao mesmo tempo, negar que os mesmos princípios se apliquem às ações individuais graças às quais essas instituições subsistem.

Quanto à segunda característica, ela não é encontrada nos princípios da concepção de justiça de Rawls justamente pelo fato de esses princípios serem princípios para a estrutura básica da sociedade. Como princípios aplicáveis a instituições, os princípios em questão são aptos a julgar processos sociais, e não os resultados desses processos. Assim entendido, o principio da diferença não é um princípio sobre a distribuição de certos bens, mas sobre processos sociais em decorrência dos quais certos bens são distribuídos. Ao tratar a estrutura básica como objeto, a justiça como equidade se caracteriza, nas palavras de Rawls, como uma concepção de justiça procedimental pura, sob a qual resultados distributivos não podem ser avaliados independentemente dos processos sob os quais foram atingidos (RAWLS, 2001, pp. 50-51). Para PC, em contrapartida, é justamente uma certa consequência distributiva que leva a reputar como injustificável a recusa ao trabalho por parte de cidadãos talentosos, seja essa uma consequência direta da recusa (a diminuição do produto social), seja indireta (a desigualdade ocasionada pelo incentivo).

Do fato de seus princípios serem princípios para a estrutura básica da sociedade e da concepção de justiça de Rawls ser uma concepção de justiça procedimental pura não se segue, por certo, que ações individuais sejam irrelevantes para a justiça ou não se sujeitem a um juízo moral. PC ainda pode, portanto, ser corroborada, embora não possa sê-lo - esse é o ponto - com base nos princípios da justiça como equidade entendidos como princípios dessa concepção - como princípios, isto é, com as duas características mencionadas acima. Repare, não obstante, que não é simples conciliar uma concepção de justiça procedimental pura, como a de Rawls, com uma concepção de justiça aplicável a resultados ou estados de coisas distributivos - na expressão do próprio Rawls, uma concepção de justiça alocativa. Concepções de justiça procedimental puras e concepções de justiça alocativas estão em permanente tensão, porque é sempre possível 
que as segundas declarem como injustos os resultados obtidos segundo as regras das primeiras.

\section{REFERÊNCIAS}

COHEN, Gerald A. (2008). Rescuing justice and equality. Cambridge, MA: Harvard University Press.

ESTLUND, David (1998). Liberalism, equality, and fraternity in Cohen's critique of Rawls. Journal of Political Philosophy, v. 6, n. 1, pp. 99-112.

HART, Herbert L. A. (1994). The concept of law. 2ed ampl. Oxford: Oxford University Press.

RAWLS, John (1999). A theory of justice. 2ed. rev. Cambridge, MA: Belknap Press.

RAWLS, John (2001). Justice as fairness: a restatement. Cambridge, MA: Belknap Press.

WALDRON, Jeremy (1981). A right to do wrong. Ethics, v. 92, pp. 21-39.

\section{Notas}

1 Os dois princípios que constituem essa concepção são enunciados por Rawls (2001, pp. 42-43) da seguinte maneira: “(a) Each person has the same indefeasible claim to a fully adequate scheme of equal basic liberties, which scheme is compatible with the same scheme of liberties for all; and (b) Social and economic inequalities are to satisfy two conditions: first, they are to be attached to offices and positions open to all under conditions of fair equality of opportunity; and second, they are to be to the greatest benefit of the leastadvantaged members of society (the difference principle)."

2 Quando John Rawls faz alusão a desacordos sobre a justiça em sociedades atuais, ele parece pressupor a precedência dos direitos sobre a justiça e até mesmo um consenso acerca da concepção de sociedade descrita acima: "Men disagree about which principles should define the basic terms of their association. Yet we may still say, despite this disagreement, that they each have a conception of justice. That is, they understand the need for, and they are prepared to affirm, a characteristic set of principles for assigning basic rights and duties and for determining what they take to be the proper distribution of the benefits and burdens of social cooperation. Thus it seems natural to think of the concept of justice as distinct from the various conceptions of justice and as being specified by the role which these different sets of principles, these different conceptions, have in common. Those who hold different conceptions of justice can, then, still agree that institutions are just when no arbitrary distinctions are made between persons in the assigning of basic rights and duties and when the rules determine a proper balance between competing claims to the advantages of social life." (TJ, p. 5 - nota de rodapé omitida).

3 "Desigualdade", no sentido que Cohen dá à palavra, é a desigualdade injusta. Pode não haver injustiça (e, portanto, desigualdade) no incentivo para realizar certo trabalho se o trabalho em questão for incomumente penoso e a remuneração adicional constituir mera compensação por esse ônus (RJE, p. 56).

4 A concepção de justiça de Rawls inclui injunções individuais (TJ, §§ 18-19), mas essas injunções têm lugar no interior de uma estrutura sujeita a certos principios que se aplicam a essa estrutura, e somente a ela.

5 Uma objeção poderia ser a de que, se a decisão do casal é justificada, então ela não constitui a estrutura injusta da divisão sexual do trabalho; o que constitui essa estrutura seriam, tão-somente, ações individuais que oneram as mulheres sem que haja boas razões para tanto. Essa objeção falha, contudo, porque os motivos que levam um casal a uma divisão desigual do trabalho doméstico são frequentemente opacos. Mesmo, portanto, que um casal esteja justificado em fazer tal divisão, é provável que essa divisão incentive a prática perversa de 
sobrecarregar (injustificadamente) a mulher com o trabalho doméstico.

6 Poder-se-ia alegar que o próprio Cohen rejeita $t 1$ ao reconhecer aos cidadãos um certo espaço de ação - o que ele chama de prerrogativa pessoal (RJE, p. 10). Essa conclusão depende, no entanto, de saber se, nos limites dessa prerrogativa, os cidadãos: a) não se sujeitam a cometer injustiça ou b) podem agir de maneira injusta, mas são autorizados a fazê-lo por algum principio que se sobrepõe à justiça. A segunda interpretação não só condiz com o pluralismo de Cohen como é corroborada pela afirmação, usada em defesa da prerrogativa pessoal, de que "we are not nothing but slaves to social justice." (RJE, p. 10). Não seria preciso, em nome da prerrogativa pessoal, resistir ao que a justiça demanda se certas ações praticadas no âmbito dessa prerrogativa não fossem injustas.

7 Ver a nota 3 acima.

8 Em uma das suas versões, o princípio da diferença permite a desigualdade na distribuição de bens primários como a renda, contanto que essa desigualdade beneficie os cidadãos em pior situação. Em outra versão, essa desigualdade - isto é, uma desigualdade que favoreça a todos, inclusive os cidadãos em pior situação - é obrigatória. Nessa última versão, o que o princípio da diferença requer, portanto, é uma estrutura básica sob a qual as expectativas dos cidadãos em pior situação sejam maximizadas. Para essas duas versões, maximizadora e não maximizadora, do princípio da diferença, ver $T J$, p. 68-69.

9 O caso em que os cidadãos talentosos "blefam" por incentivos - isto é, o caso em que eles estariam dispostos a trabalhar de maneira socialmente desejável mesmo à falta de incentivo - é irrelevante para o argumento de Cohen, já que esses incentivos são proibidos tanto pela versão estrita quanto pela versão frouxa do principio da diferença (RJE, pp. 57-58).

10 Mais ainda, não parece que a escolha entre as interpretações estrita e frouxa dependa de informações que não estão disponíveis para as partes na posição original e que só se fazem disponiveis nas etapas posteriores da sequência de quatro estágios de implementação da justiça como equidade. Sobre essa sequência, ver TJ, § 31 .

11 Outra condição, além das duas mencionadas acima, é a de que a expectativa em questão seja fundada, isto é, a de que tenhamos razão para prever que à lei se seguirá um certo comportamento.

12 A lei em questão tanto pode ser uma lei que regula as trocas de maneira a permitir que trabalhadores cujas capacidades estejam em alta demanda sejam desigualmente remunerados como uma lei fiscal "generosa" graças à qual esses trabalhadores conservem, ao menos em parte, o produto dessas trocas.

13 Por exemplo, na hipótese em que a realização de um certo trabalho não dependa de um estado anímico que o trabalhador somente seria capaz de alcançar mediante incentivo.

14 Doravante, como "recusa ao trabalho" se deve entender acima a recusa por parte de um cidadão talentoso seja ao trabalho em si, seja ao trabalho em uma certa área de atividade.

15 Cohen admite a dificuldade de que a totalidade da legislação seja justificada abrangentemente. Leis penais, por exemplo, ao que tudo indica, não se prestam a uma justificação assim. Segundo Cohen, o fato de termos de nos contentar com uma justificação menos do que abrangente para certas leis é um sinal de que algo não vai bem (RJE, p. 41, nota 15$)$.

16 Estou de acordo com ambas as premissas, inclusive com a segunda, a mais substancial delas.

17 Que outro sentido se poderia dar a "justificável” no contexto acima? Podemos cogitar de um sentido mais forte segundo o qual algo só é justificável se houver uma ou mais razões morais suficientes para que aconteça (de modo que a mera falta de uma razão em contrário não seja suficiente para a justificabilidade). Contra esse sentido mais forte, porém, deve-se ponderar que se trata acima de um comportamento individual - o comportamento de cidadãos talentosos que, à falta 
de incentivo, recusam-se a dar certo uso à sua força de trabalho. Em casos, ademais, em que o sentido mais forte de justificável parece mais adequado quando se trata, por exemplo, da ação coerciva do estado - pode ser que a natureza da ação mesma ofereça uma razão pro tanto para que ela não se realize, de modo que, ao demandar por razões, estamos demandando por razões que não apenas favoreçam a ação em questão como também se contraponham a uma certa razão (por exemplo, a razão decorrente do seu caráter coercivo) contrária à sua realização.

18 RJE, p. 187: "Liberalism does not require that you exercise the sovereignty it grants in accordance with your other-things-equal first preferences, and without regard to what you might lose by doing so when other things aren't equal. The liberal right to decide what to read does not require me to read what I initially prefer to read, in advance of considering the full consequences of my doing so. There is no such restriction in the usual understanding of a liberal right."

19 De maneira bastante clara, ver RJE, p. 215: "But we have now seen that it does not follow from denying that the doctor-gardener should be forced to doctor that there is nothing wrong in her getting whatever pay she can get for agreeing to be one. The 'unequal income inference,' which proceeds from the premise that $A$ should not be forced to work as a doctor to the conclusion that anything goes, morally speaking, about the terms she sets for being a doctor, is invalid." (nota de rodapé omitida). Não posso me ocupar aqui da questão de saber se um direito moral pode ser exercido de maneira moralmente equivocada (ou se, ao contrário, ter um direito moral implica que qualquer exercicio de tal direito seja moralmente licito). $\mathrm{O}$ direito à liberdade de ocupação é concebido acima como um direito moral ou político, e não como direito estritamente jurídico, de maneira que, se estiver correta a tese segundo a qual direitos morais não podem ser exercidos de maneira imoral, o argumento do direito à liberdade de ocupação invalida PC. Sobre esse tema, ver Waldron (1981).

20 Esses exemplos se assemelham ligeiramente aos usados por David Estlund (ESTLUND, 1998) contra a critica aos incentivos de Cohen, mas é importante reparar em algumas diferenças. $\mathrm{O}$ argumento de Estlund é o de que, se Cohen confere certo espaço de ação egoísta aos cidadãos talentosos (isto é, um espaço no qual esses cidadãos estão autorizados a perseguir seu próprio interesse em detrimento do que a justiça demanda), então ele precisaria admitir também que a justiça seja posta de lado por certas motivações não egoístas (como afeições), bem como por razões morais, ainda que mais fracas do que as razões de justiça. $\mathrm{O}$ que Estlund tem em vista, portanto, não são necessariamente hipóteses em que a recusa do cidadão talentoso a trabalhar em favor dos mais pobres esteja, ao fim e ao cabo, justificada, mas apenas hipóteses em que a motivação para essa recusa seja mais louvável do que o simples egoísmo. Para a resposta de Cohen a Estlund, ver RJE, pp. 387-394.

21 Para prevenir a objeção de que a renda adicional ganha como advogado é mera compensação por um trabalho que ocupa mais tempo (o que descaracterizaria o aumento de renda como incentivo que confere a João uma vantagem), presuma que, nos dois exemplos, o tempo total despendido com as aulas e a advocacia é o mesmo. É apenas a natureza da atividade (por exemplo, o fato de a advocacia ter de ser exercida por um certo número de horas continuas) que impediria João de se ocupar, como advogado, do trabalho de cuidado que atualmente realiza. 